\title{
Republicanismo y participación ciudadana en el diseño político-jurídico de la nueva Constitución de la República de Cuba de 2019 1
}

Republicanism and citizen participation in the political-legal design of the new Constitution of the Republic of Cuba of 2019

Republicanismo e participação cidadã no desenbo político-jurídico da nova Constituição da República de Cuba de 2019

Républicanisme et participation citoyenne à la conception politico-juridique de la nouvelle Constitution de la République de Cuba de 2019 共和主义和公民参与两千零一十九年古巴共和国新宪法 的政治法律设计

Joanna González Quevedo Universidad de La Habana - Cuba

Revista Derechos en Acción ISSN 2525-1678/ e-ISSN 2525-1686

Año 5/No 16 Invierno 2020 (21 junio a 20 septiembre), 333-358

DOl: https://doi.org/10.24215/25251678e426

Recibido: 01/06/2020

Aprobado: 01/08/2020

1 Constitución de la República de Cuba de 10 de abril de 2019 publicada en Gaceta Oficial Extraordinaria No.5. AÑO CXVII.

2 Profesora principal de Derecho Romano. Facultad de Derecho. Universidad de la Habana. Cuba. Licenciada en Derecho, La Habana 2006. Máster en Derecho Constitucional y Administrativo, La Habana, 2010. Doctora en Ciencias Jurídicas, La Habana, 2014. Culminó sus estudios doctorales en la Universidad de Buenos Aires en julio de 2014. Realiza estudios post doctorales sobre República y participación ciudadana en las Universidades de Verona, Padova y Bologna, Italia. Emails: joannagonzalez3@lex.uh.cu y joannaglez1983@gmail.com (ORCID: https://orcid.org/0000-0001-6478-5853). 
Resumen: Este ensayo tiene como objetivo argumentar cómo una adecuada construcción teórica de la recepción de los principios del republicanismo romano en Cuba, puede contribuir al perfeccionamiento jurídico de la participación política del ciudadano, como esencia del diseño político-jurídico nacional. Como consecuencia de lo anterior, se imponen varias interrogantes: ¿cómo se aprecia la presencia o no de los principios del republicanismo romano en la nueva Constitución del año 2019 y otras disposiciones normativas referentes al derecho de participación?, ¿Qué deficiencias fueron superadas en la concepción ordenadora de la participación política del ciudadano, en consonancia con las bases republicanas y democráticas sobre las cuales se asienta, en el diseño político-jurídico nacional? Esta última interrogante es vital para que no fracase el proceso de cambios. No basta sólo tener en cuenta los fundamentos romanistas presentes en el Magno texto, sino que también la fundamentación, desde una visión iusrepublicana, ha de proponer modificaciones en la concepción ordenadora de la participación política, para contribuir al perfeccionamiento de la democracia en la República de Cuba.

Palabras clave: Recepción, Derecho Romano, República, Democracia en Cuba.

\begin{abstract}
This essay has as objective to argue how an appropriate theoretical construction of the reception of the principles of the Roman republicanism in Cuba, it can contribute to the juridical improvement of the citizen's political participation, as essence of the national design political and juridical. As the above-mentioned consequence, several questions are imposed: how is the presence appreciated or not of the principles of the Roman republicanism in the defined political lines starting from the Sixth Congress, of face to the unavoidable bring up to date of the New Constitution from 2019 and other relating normative dispositions to the participation right?, What deficiencies are they present in the conception of the citizen's political participation that are incongruous with the republican and democratic bases on which settles, in the national political-juridical design? This last query is vital so that the process of changes doesn't fail. It only is not enough to keep in mind the foundations of the Roman law in the lines that must guide the improvement, but rather also the foundation, from a vision of the Republic, it must propose modifications in the conception of the political participation, to contribute to the improvement of the democracy in the Republic of Cuba.
\end{abstract}


Keywords: Reception, Roman Law, Republic, Democracy in Cuba.

Resumo: Este ensaio tem como objetivo argumentar como uma construção teórica adequada da recepção dos princípios do republicanismo romano em Cuba, pode contribuir para a melhoria jurídica da participação política do cidadão, como essência do desenho político-jurídico nacional. Como consequência do anterior, prevalecem várias questões: Como pode ou não ser apreciada a presença dos princípios do republicanismo romano na nova Constituição de 2019 e noutras disposições normativas referentes ao direito de participação?, que deficiências foram superadas na concepção organizativa da participação política do cidadão, em consonância com as bases republicanas e democráticas em que se baseia, no desenho político-jurídico nacional? Esta última questão é vital para que não falhe o processo de mudança. Não basta só ter em conta apenas as fundamentos romanistas presentes no Magno Texto, mas também a fundamentação, a partir de uma visão jusrepublicana, tem que propor modificações na concepção organizadora da participação política, para contribuir a melhoria da democracia na República de Cuba.

Palavras-chave: Recepção, Direito Romano, República, Democracia em Cuba.

Résumé: Cet essai vise à démontrer comment une construction théorique adéquate de la réception des principes du républicanisme romain à Cuba peut contribuer à l'amélioration juridique de la participation politique du citoyen, en tant qu'essence de la conception politico-juridique nationale. En conséquence de ce qui précède, plusieurs questions se posent: comment la présence ou non des principes du républicanisme romain est-elle appréciée dans la nouvelle Constitution de 2019 et dans d'autres dispositions normatives relatives au droit de participation? Quelles lacunes ont été surmontées dans le Organiser la conception de la participation politique citoyenne, en accord avec les bases républicaines et démocratiques sur lesquelles elle se fonde, dans la conception politico-juridique nationale? Cette dernière question est vitale pour que le processus de changement n'échoue pas. II ne suffit pas seulement de prendre en compte les fondations romanistes présentes dans le Grand Texte, mais aussi la fondation, d'un point de vue républicain, doit proposer des modifications dans la conception ordonnatrice de la participation politique, pour contribuer à l'amélioration de la démocratie dans la République de Cuba. 
Mot-clés: Réception, droit romain, République, démocratie à Cuba

摘要：本文旨在论证，对古巴的罗马共和主义原则的接受进行适当 的理论建构，如何能作为国家政治法律设计的实质，促进公民政治 参与的法律改善. 由于上述原因, 提出了几个问题:两千零一十九年 新宪法和有关参与权的其他规范性规定如何赞赏罗马共和主义原 则的存在?在国家政治法律设计中，根据公民所基于的共和制和民 主基础来组织公民的政治参与构想?最后一个问题至关重要，因此 更改过程不会失败. 不仅考虑到大文本中存在的罗马人基础，而且 从欧共体的角度来看，该基础还必须对政治参与的秩序概念提出修 改, 以促进共和国民主的发展古巴.

关键字: 接待, 罗马法, 共和国, 古巴民主

\section{Principios informantes del republicanismo democrático romano}

La esencia del presente estudio se encuentra en la fundamentación de los aportes del republicanismo romano para la recepción del Derecho Público Republicano Romano en América Latina, fundamentalmente en Cuba. Como dirían los romanos "de cada cosa, el principio es la parte esencial". Por tal razón, este trabajo es una muestra de la oportunidad y la preocupación científica de encontrar, en los orígenes del modelo iuspublicístico romano, las bases de una temática esencial para la contemporaneidad, como lo es la participación ciudadana. Como pauta el libro 1 del Digesto Justinianeo, la investigación se abocó al estudio de la historia vital del sistema romanista y no al análisis del sistema romanista disuelto en la historia como mera referencia antigua.

El tema de la recepción del iusrepublicanismo romano, particularmente en Cuba, no obstante, su aludida trascendencia, adolece de un escaso abordaje científico. Asistimos así a

3 Cfr. D. 1. 2. 1. García del Corral, Idelfonso, Cuerpo del Derecho Civil Romano, primera parte Instituta-Digesto, Ediciones. Antiguas y Modernas, Barcelona, 1889, p. 5. 
una insuficiente construcción teórica que fundamente la recepción del iusrepublicanismo romano en Cuba. Esto ha traído como consecuencia un desconocimiento de las auténticas raíces patrias y, por tanto, de los orígenes y los principios romanistas que ha recibido el republicanismo cubano en materia de participación política.

Desde las ciencias jurídicas-especialmente en los estudios de Derecho Romano-, es poco frecuente las sistematización, con un carácter integral y uniforme, de las bases del republicanismo democrático romano y su impronta para la unidad de principios del sistema de Derecho continental desde una visión iuspublicística, amén de la existencia de valiosos ensayos y autores, estudiosos del Derecho Público Romano. ${ }^{4}$

La importancia del conocimiento de los principios que extraídos del Derecho Romano siguen siendo como la propia historia en que se generaron y tienen el propio rango de esta, constituye un imperativo para cualquier estudioso del romanismo. Ello obliga a ser, parafraseando a CicERón, testigo de los tiempos, luz de la verdad, vida de la memoria, y mensajeros de la antigüedad ${ }^{5}$.

Entonces, sobre la base de los fundamentos históricos del iuspublicismo romano y del estudio detallado de sus fuentes originarias de conocimiento, veamos cuáles pueden considerarse, los principios informantes del Iusrepublicanismo romano ${ }^{6}$ :

4 Entre otros trabajos, pueden verse, Catalano, Pierángelo, Constitución y constitucionalismo hoy, ob.cit, Fernández Bulté, Julio, Separata de Derecho Público Romano, ob.cit; Fernández de Buján, Antonio, Derecho Público Romano, Ed. Civitas, decimocuarta edición, 2011; Fernández Estrada, Julio Antonio, De Roma a América Latina: El tribuno del pueblo frente a la crisis de la República, ob.cit; Lobrano, Giovanni, "Republica e municipi”, en Costituzionalismo Latino II, Consiglio Nazionale delle Ricerche Progetto Italia - América Latina, 1996; RINALDI, Norberto, Lecciones ampliadas de Derecho Romano, 1ra Edición, Buenos Aires, 2007; RuBIo CorreA, Marcial, "La participación del pueblo en la elaboración constitucional dentro de los países latinoamericanos de Sudamérica", en Costituzionalismo Latino II, Consiglio Nazionale delle Ricerche Progetto Italia - América Latina, 1996 ; Torrent, Armando, Derecho Público Romano y sistema de fuentes, Edisofer S.L, Zaragoza, 2002;

5 Cicerón, De República, En NAVARRO Y CALVO, Francisco, (Traductor), ob.cit, p. 140.

6 González Quevedo, Joanna, "Principales aportes del modelo clásico de Derecho Público Republicano Romano para la unidad de principios del republicanismo democrático", en Revista 
1. La Respublica es la organización política del populus romano. 2. La potestas (soberanía) del populus es la base de la Respublica.

2.1 La potestas reside en el pueblo, es indelegable y se ejerce a través de instituciones de participación, desde el nivel municipal y hasta el nivel central de ejercicio del poder.

2.1.1 La potestas es indivisible, por lo que el poder no se puede dividir.

2.1.2 Ley pública como máxima expresión de la potestas republicana.

3. Existencia del poder negativo directo contra actos lesivos a la potestas del populus.

4. Dada la complejidad de la ejecución de las decisiones políticas, para el ejercicio efectivo del gobierno deben elegirse funcionarios específicos denominados magistrados.

4.1 Los cargos políticos o magistraturas deben ser ejercidos por un cierto período de tiempo, son revocables y deben ser ireelegibles de forma inmediata.

En efecto, el populus romanus no era una abstracción inasible, sino el resultado de la concreta y específica sumatoria de los ciudadanos organizados tanto a nivel de la ciudad de Roma como de los municipios ${ }^{7}$. La soberanía, concretada mediante los mecanismos de participación ciudadana, constituía la base de la Respublica y era absolutamente indelegable de la misma manera que hoy es indelegable el ejercicio del sufragio. Respecto a la indelegabilidad, constituye una consecuencia lógica del origen miliciano de los primeros comicios, donde los soldados se pronunciaban con las armas en la mano. En esos casos, sólo los ciudadanos-soldados romanos presentes podían manifestar su

española de Republicanismo "Sin Permiso" disponible en www.sinpermiso.info/articulos/ ficheros/11romano.pdf, pp. 5-7.

7 Rinaldi, Norberto Darío, "La resurrección del Derecho Público Romano" en, Memorias del XIII Congreso Latinoamericano de Derecho Romano, La Habana 2002, editadas por Universidad de San Nicolás de Hidalgo, Morelia, México, p. 231. 
libertad sufragando a través de sus aclamaciones. El principio de la "libertad popular" implicaba al decir de Catalano ${ }^{8}$ la intervención inmediata de los ciudadanos en el ejercicio del poder popular soberano a través de instituciones que se concretan en dos procesos fundamentales: discusión-veto (intercessio) -aprobación-abrogación de las leyes y elección-revocación de los magistrados.

Nótese que Catalano habla de intervención inmediata. Ahora bien, algunas interrogantes se imponen al respecto en un orden clasificatorio: ¿Toda participación directa es a la vez inmediata? Y en consecuencia, ¿todas las instituciones romanas de democracia directa pueden ser consideradas instituciones de participación inmediata de cara a la tesis del republicanismo democrático? Y por último, ¿cabe hablar de participación indirecta en el republicanismo romano?

Con apego al étimo de los términos, se advierte que lo directo presupone una acción que se encamina o dirige a determinados fines, mientras que lo inmediato implica que esa actividad produzca efectos próximos en el tiempo, sin mediaciones impeditivas de su eficacia y del carácter vinculante de lo que decida el soberano. Toda participación política por antonomasia es directa en tanto se encamina a que los ciudadanos tomen parte por sí mismos en los procesos decisorios. El carácter directo de la participación es un presupuesto de la cualidad de lo inmediato, por lo que no cabe hablar de participación indirecta en un modelo político como el romano, que por ser indelegable la potestas no conoció la institución de la representación.

La teoría clásica de la representación política ${ }^{9}$, tiene como principales presupuestos la prohibición del mandato imperativo,

8 Catalano, Pierángelo, "Choque de sistemas jurídicos en la perspectiva latinoamericanista", en Memorias del XV Congreso latinoamericano de Derecho Romano, Morelia 2006 p.31. Según refiere el autor para el Libertador Simón Bolívar el principio de la libertad popular nace en Roma y supone la intervención inmediata en el ejercicio del poder.

9 Vid. Duguit, León, Manual de Derecho Constitucional, pp. 122 y 123 cuando analiza las consecuencias de considerar la representación política como una "situación objetiva jurídica 
la negación de una relación de derechos subjetivos entre los representantes y los representados, la trascendencia de la elección y el derecho al sufragio, la tripartición de poderes y el control horizontal entre los poderes.

En el Derecho romano, solo se conoció posteriormente, en la época clásica, con el desarrollo de las relaciones sociales, pero limitado al ámbito privado. A medida que se desarrollan las relaciones, la necesidad de poder hacerse representar por terceros en los actos jurídicos viene a ser más indispensable. Solo mucho más tarde, en la época clásica, es cuando el Derecho romano se eleva hasta la concepción de esas formas que satisfacen a esta necesidad. La razón de ello es que desde los tiempos más antiguos, ese derecho poseía dos formas propias para realizar el objeto de la representación jurídica, formas que pasan al derecho nuevo.

La primera consistía en el empleo de personas sometidas al poder de otro, y estaba basada en el principio de que todo lo que esas personas adquieren recae en el sustentador del poder. Esta forma tenía, sin embargo, el defecto de no poder hacerse extensiva a la representación en justicia.

Pero una segunda forma-que tuvo otros destinos- vino a llenar ese vacío. Un mandatario concluía el negocio a su propio nombre y después transfería al demandante los efectos de su acto. Cuando en la época antigua se quería hacer representar en justicia, no había otro recurso que transferir fiduciariamente al mandatario la relación o el objeto litigio. En tal sentido, SAVIGNY $^{10}$ alude a dos momentos en los que la representación alcanzó distintas dimensiones. Además, admite como IHering,

\footnotetext{
de hecho" Citado por Guzmán Hernández, T. Yan, "Representación en política, instituciones de democracia directa y revocatoria de mandato en Venezuela - Una manera de interpretar el modelo normativo-constitucional venezolano de participación política”, Tesis en opción al grado de Doctor en Ciencias Jurídicas, Facultad de Derecho, Universidad de la Habana, La Habana, 2008, p. 35-38.

10 Savigny, M. F. C., Sistema de Derecho romano actual, F. Góngora y Compañía, Madrid, 1879, pp.207-210.
} 
que el aumento de las transacciones sociales trajo consigo la ampliación de la órbita de la representación en el Derecho romano.

Efectivamente, la representación permite la intervención de los actos libres en las relaciones de derecho concernientes a los impúberes, los enajenados y los pródigos, lo cual sería imposible sin ello. Así, la representación no halla más que dos aplicaciones insignificantes en el derecho de familia y respecto al derecho de sucesión, que no tiene por objeto regular las dos posiciones de los bienes entre vivos, sino su transmisión de una generación a otra.

En materia de obligaciones, la representación se aplica a las transacciones mismas, es decir, a las relaciones de persona a persona, pero no a la reparación necesaria que lleva consigo la violación del derecho. En los tiempos muy antiguos encontramos el principio riguroso de que ninguno podía ser representado más que por las personas que están bajo su dependencia, y solo para adquirir, nunca para disminuir sus bienes.

Mas un principio tan estrecho y riguroso no podía mantenerse cuando la civilización había aumentado las transacciones sociales, y fue admitiéndose poco a poco la mediación, si bien limitada a ciertos casos. Comenzó la reforma respecto a las adquisiciones de la posesión y a los medios de adquirir la propiedad fundada en aquella, tales como la tradición y la ocupación. Después se admitió la representación para las enajenaciones resultantes de la tradición y para las adquisiciones del mismo género, permitiéndose en todos los casos hacerse representar ya por los hijos ó los esclavos, ya por personas libres. De este modo, en lo referente a las traslaciones de la propiedad, no se excluyó la representación libre sino para las antiguas formas del derecho civil primitivo, la mancipación y la iure cessio.

El poder para los romanos era indivisible no sólo en el Derecho Público, sino también en el Derecho Privado. Con relación a este último, por ejemplo, la manus (autoridad del esposo sobre 
la esposa) y la patria potestas (poder del pater familias sobre los hijos y demás descendientes legítimos alieni iuris), no admitían más que una voluntad determinante, la del sujeto que detentaba esos poderes. Ese concepto de indivisibilidad en el Derecho Privado tiene su consecuente reflejo en el Derecho Público.

La ley pública debe ser entendida como resultado de la voluntad mayoritaria del pueblo en la creación del Derecho Republicano. Sentencia Fernández Estrada ${ }^{11}$ que el ciudadano romano no era oprimido ni por el orden político en que vivían, ni por el Derecho que regulaba su vida, porque ese orden político era justamente el que él se había dado soberanamente, y el Derecho era absolutamente creado por el ciudadano. A ello se refería Juan Jacobo Rousseau, en Contrato Social. II, 12, como "costumbres", "hábitos" u "opinión", al referirse a una categoría de leyes "...que no se graba ni sobre mármol ni sobre bronce, sino en los corazones de los ciudadanos, que es la verdadera constitución del Estado; que toma todos los días nuevas fuerzas; que, en tanto otras leyes envejecen o se apagan, ésta las reanima o las suple [...] elemento desconocido para nuestros políticos, pero de la que depende el éxito de todas las demás [leyes políticas, civiles y criminales] y de la que se ocupa en secreto el Gran Legislador, mientras parece limitarse a reglamentos particulares, que no son sino la contra de la bóveda, en la cual las costumbres, más lentas en nacer, forman, al fin, la inquebrantable clave ${ }^{12}$ ". La libertas consiste en la sumisión voluntaria a la ley votada en común, de donde se deriva que la lex publica es uno de los vínculos más fuertes, o el de mayor cohesión entre los ciudadanos romanos.

El papel que los tribunos tenían reservado en el sistema constitucional republicano, no era otro que el de proteger primero a los plebeyos y luego a todos los ciudadanos, de los abusos que

\footnotetext{
11 Fernández estrada, Julio Antonio, “El tribunado; sus expresiones posibles en la crisis del actual modelo iuspublicístico", ob.cit, p. 22

12 Cfr. ROUSSEAU, Jean-Jacques, El contrato social, Ed. Tecnos (Grupo Anaya SA), Madrid 200 , p. 54.
} 
pudieran cometer los magistrados como mandatarios del pueblo. Conforme a la opinión de Rousseau, esa institución servía en Roma para proteger al soberano, es decir al pueblo, de quienes ejercen el gobierno. Obviamente la garantía constitucional no podía estar a cargo de los funcionarios ordinarios, porque es precisamente de los abusos de esos funcionarios que hay que proteger al ciudadano común. Por tanto, si le fueran suprimidas al populus sus instituciones de participación como la aprobación y abrogación de la ley, la intercessio, la elección de los magistrados y la revocación les queda como último recurso del derecho de resistencia como manifestación del poder negativo directo y de la soberanía popular ${ }^{13}$.

En coincidencia con Fernández Butté ${ }^{14}$ se asiente en que para los romanos particularmente, el poder soberano del populus, la potestas-que era indelegable e intransferible-, se ejercía directamente a través de los Comicios, tanto Curiados, como Tribales, y después de Servio Tulio, los Centuriados. Sin embargo, está claro que hay muchísimas acciones que no puede hacer todo el populus reunido en comicios, que requieren diligencia y acción personal, es decir, personas encargadas de determinadas misiones, que podríamos llamar, "de gobierno". Para ello la iuspublicística echó mano al mandato el cual es un contrato consensual nacido en Roma, por el cual una persona llamada mandante, que dispone de total lucidez y capacidad, ordena a otra llamada mandatario, que haga a su nombre tal o cual

\footnotetext{
13 Durante la existencia de la respublica romana se produjeron una serie de secesiones, protagonizadas por el plebeyado en búsqueda de reformas y concesiones políticas, económicas y sociales. Al igual que el tribunado, el origen de la secessio plebis debe buscarse en la fuerza pujante de una clase y sector social que lucha por encontrar espacio para sus demandas e intereses en el aparato de poder político de la civitas, el cual como ya analizamos fue hasta cierto momento, instrumento de poder exclusivo del patriciado. Por lo tanto, junto a la actividad de los tribunos se erige entonces la secesión como mecanismo o instrumento a través del cual el plebeyado puede hacer influencia en la vida política de la ciudad. De esta serie de secesiones (cuya cantidad total no está definida) se señala como la más relevante, debido a su impacto y consecuencias, la ocurrida en 494 a.n.e., lo sucedido durante esa secesión fue totalmente sutil e innovador.
}

14 Cfr. FERNÁNDEZ BULté, Julio, Separata de Derecho Público Romano, ob.cit, pp. 25-30. 
gestión, cumpla tal o cual orden o mandato. Por supuesto, el mandante no enajena su personalidad ni su voluntad, sino que cede algo de su autoridad para que el mandatario haga determinadas diligencias a nombre suyo. $\mathrm{Y}$ por supuesto, el mandante vigila el cumplimiento del mandato, lo controla y se reserva el derecho de revocar el mandato en cualquier momento.

Pese a la miopía con que los historiadores liberales decimonónicos interpretaron al mundo romano, en la vieja república romana jamás se practicó la representación. Los romanos no lo hubieran admitido. No hubieran cedido jamás su potestas, ni hubieran enajenado su intervención en la respublica, la cosa de todos. Cuando designaban magistrados, los consideraban simples mandatarios, nunca representantes. Las pruebas de ello son abrumadoras. Nunca dejaron las manos sueltas a los magistrados; el Tribuno con su jus vetus y su sacer era una fuerza de contención, un poder negativo como ha subrayado CATALANO.

Además siempre se reservaron la secesión o resistencia como última alternativa de su poder, indelegable e indivisible. Los romanos eran lo suficientemente soberbios como para admitir que ellos no podían dirigir los asuntos o la cosa pública, todos en general y cada uno en particular.

Finiquitando, concluye al respecto Fernández Estrada ${ }^{15}$ que fue nuevamente J.J. Rousseau quien penetró con mirada más profunda en el pensamiento del populus romano al respecto. El ginebrino afirma que en el funcionamiento de la república romana habría que distinguir siempre entre la potestas-poder soberano exclusivo del populus- y la misión del gobierno. Para ejecutar la voluntad ya legislada por el pueblo, a esos magistrados se les otorgaba la ya aludida cuota de auctoritas, es decir, una encomienda política específica.

De ello se desprende algo que Rousseau explica con suspicacia y no siempre ha sido debidamente entendido: que el hombre romano era soberano y súbdito al mismo tiempo. Soberano por

15 FERNÁNDEZ ESTRADA, Julio Antonio, "El tribunado; sus expresiones posibles en la crisis del actual modelo iuspublicístico", ob.cit, p. 29. 
que mantenía siempre su poder como parte de la comunidad política. Y súbdito porque debía en cada momento someterse al gobierno, es decir, a las decisiones de las magistraturas. Como afirma Rousseau, entre esos dos valores no había contradicción. Cuando el ciudadano obedecía a su gobierno, no enajenaba su condición de soberano, sino que la realizaba en un plano más alto y concreto. Al obedecer al gobierno estaba, de hecho, obedeciendo a aquellos que él mismo había elegido y obedeciéndolos en aquello que él mismo había dispuesto como soberano.

De ahí emana una conclusión no siempre calada en toda su hondura: la forma de gobierno carece de importancia. No importa que sea una monarquía o un gobierno colegiado; no importa incluso que sea elegido mediante el sorteo, puesto que el gobierno no puede hacer sino aquello que le está encomendado, y no otra cosa, incapaz de separarse de la voluntad popular.

El sistema romano se inspira en el deseo de evitar que las magistraturas se perpetuasen en manos de quien las desempeñaban. No solo está prohibida la acumulación de distintas magistraturas, sino también que un mismo ciudadano ejerciese igual cargo o funciones diferentes durante varios años consecutivos. Opina Arangio-Ruiz ${ }^{16}$ que para evitar la perpetuación en el poder se prohibió que un ciudadano fuera reelecto en una magistratura, se vedó que detentara magistraturas distintas sin dejar pasar un tiempo con la anterior. Tal reelección, primero fue reglamentada severamente y luego suprimida.

\section{La recepción de los principios del Derecho Público romano en el diseño de la participación política del ciudadano en la República de Cuba. Retos para su perfeccionamiento}

Este epígrafe tiene como objetivo argumentar cómo una adecuada construcción teórica de la recepción de los principios

16 Arangio-Ruiz, Vicente, Historia del Derecho Romano,4ta edición, Biblioteca Jurídica de Autores Españoles y Extranjeros, p. 120. 
del iusrepublicanismo romano en Cuba, puede contribuir al perfeccionamiento jurídico de la participación política del ciudadano, como esencia del diseño político-jurídico nacional. Para ello, lógicamente, se analizaron las normas jurídicas que están vigentes en materia de participación.

Sin embargo, no se pueden ignorar las pautas que trazó el Sexto Congreso del PCC y las políticas de actualización del modelo socialista cubano aprobadas por este, si se tiene en cuenta que uno de los retos fundamentales a enfrentar en los próximos años será el desarrollo de normas complemetarias al texto constitucional. En dicho proceso deberán considerarse los principios del iusrepublicanismo romano, provenientes de lo más avanzado y universal de la teoría democrática, cuyos orígenes se remontan al Derecho Público Republicano Romano.

Es por ello que no resulta disonante fundamentar, desde los orígenes y los principios romanistas que ha recepcionado el actual diseño de la participación política del ciudadano, las principales líneas que deben guiar el perfeccionamiento democrático del diseño político-jurídico nacional.

Como consecuencia de lo anterior, se imponen varias interrogantes: ¿cuáles son las principales líneas políticas que deben guiar el perfeccionamiento democrático del diseño políticojurídico nacional, de acuerdo a la actualización del proyecto socialista?, ¿cómo se aprecia la presencia o no de los principios del iusrepublicanismo romano en las líneas políticas definidas a partir del Sexto Congreso, de cara a la nueva Constitución cubana de 2019 y otras disposiciones normativas referentes al derecho de participación?, ¿Qué deficiencias están presentes en la concepción ordenadora de la participación política del ciudadano, que resultan incongruentes con las bases republicanas y democráticas sobre las cuales se asienta, en el diseño políticojurídico nacional?

Esta última interrogante es vital para que no fracase el proceso de cambios. No basta sólo tener en cuenta los fundamentos romanistas presentes en las líneas que han de guiar el 
perfeccionamiento, sino que también la fundamentación, desde una visión iusrepublicana, ha de proponer modificaciones en la concepción ordenadora de la participación política, para contribuir al perfeccionamiento de la democracia en la República de Cuba.

Estas interrogantes y presupuestos guiarán la fundamentación de las principales líneas que deben conducir al perfeccionamiento democrático del diseño político-jurídico nacional, y que a continuación se analizarán:

a) Fortalecimiento de la institucionalidad democrática y responsabilidad de los mandatarios en el ejercicio del poder a través del control popular de su gestión.

Entre las principales líneas políticas que trazó el Informe Central al VI Congreso del Partido Comunista de Cuba, en el marco del perfeccionamiento, está el fortalecimiento de la institucionalidad. Dándose continuidad a lo anterior, la introducción a los objetivos de trabajo aprobados por la Primera Conferencia Nacional del PCC, aprobó como uno de sus objetivos la necesidad de incentivar la participación real y efectiva de la población en la toma de decisiones, así como fortalecer el control popular sobre los órganos competentes .

Evidentemente, esta proyección está afianzada sobre fundamentos republicanos romanistas, que colocan a la soberanía popular y la participación ciudadana como centro del proceso. Siguiendo a CATALANO, el principio de la soberanía popular en una República democrática como fue la romana implicaba la intervención inmediata de los ciudadanos en el ejercicio del poder popular soberano a través de la institucionalidad democrática. La misma se concretaba en instituciones fundamentales: discusión pública y consulta para la aprobación-abrogación de las leyes y elección-rendición de cuentas-revocación de los mandatarios.

Desde una posición eminentemente crítica en pos del perfeccionamiento de la democracia en Cuba, y sin que constituya una discordancia con la tesis que se defiende de que 
ciertamente en Cuba existe una República democrática fundada en principios romanistas, cabría preguntarse detenidamente: ¿todas las instituciones de participación, en el diseño políticojurídico cubano actual, pueden ser consideradas instituciones de participación inmediata de cara a la tesis del republicanismo democrático romano?, ¿qué no es republicano al estilo romano en nuestro diseño participativo y dónde debemos perfeccionar nuestras instituciones para ser coherentes con los principios del republicanismo democrático que nos legó nuestra historia constitucional?

De conformidad con los requisitos expuestos y sobre la base de la clasificación de los mecanismos de participación y de la tipología de los institutos participativos en Roma, podemos concluir que para hablar de una institucionalidad democrática de base romanista hay que tener en cuenta que:

Primero: El procedimiento de realización de las instituciones debe provenir "desde abajo" o sea cuando es la propia ciudadanía quien promueve el proceso participativo, o cuando activándola un magistrado o mandatario la decisión del pueblo de aceptarla o no es vinculante (dígase ad referéndum), verbigratia: discusión pública y consulta para la aprobación-abrogación de las leyes y nominación-elección-rendición de cuentas-revocación de los mandatarios. Segundo: Aquellas cuya aceptación no está mediada por valoraciones de los órganos estatales o existe una mínima valoración, verbigratia: discusión pública y consulta para la aprobación-abrogación de las leyes y nominación-elecciónrendición de cuentas-revocación de los mandatarios. Tercero: Aquellas que se pueden activar tanto a nivel central de la ciudad de Roma como al interior de cada municipio.

Procédase, pues, a un estudio detallado de las instituciones de participación y véase cuáles con un origen popular exhiben efectos inmediatos y vinculantes en la concepción ordenadora de la participación política del ciudadano en Cuba.

La Constitución cubana de 2019, regula la participación política en el entendido de que todos los ciudadanos, con capacidad 
legal para ello, tienen derecho a intervenir en la dirección del Estado, bien directamente o por intermedio de sus representantes elegidos para integrar los órganos del Poder Popular. Entre ellas, se defiende la participación en elecciones periódicas y nominación de candidatos y en referendos populares, las consultas, la rendición de cuentas, la revocación y la iniciativa legislativa popular.

Resulta válido recordar que en Roma la nominación de los candidatos podía provenir de los ciudadanos y de otro ente del aparato estatal, dígase un magistrado o mandatario. Lo que sí era facultad exclusiva del populus era la elección y revocación de todos los cargos de elección popular. Esto era factible no sólo en la ciudad de Roma, sino a nivel de los municipios, en los cuales podían ser nominados y elegidos como mandatarios de la curia municipal magistrados con imperio en el nivel central de la ciudad romana. Los magistrados podían ser revocados a iniciativa de los ciudadanos, e incluso en estos espacios municipales se podían someter a consulta proyectos de leyes para la civitas romana. En este último aspecto, nos alejamos del modelo romano-latino en sede de participación popular.

Es que aquí también el ordenamiento desaprovecha las consecuencias del voto directo y se aleja de la inmediatez que debe caracterizar a la participación republicana. Los delegados a las Asambleas Provinciales y los diputados a la Asamblea Nacional del Poder Popular, son electos directamente por la ciudadanía y rinden cuenta ante ella. Pero serán revocados por las asambleas que los nominaron, no por los electores, lo que resulta consistente con un punto antes argumentado: son agentes de los órganos estatales superiores.

La revocación de los cargos en Cuba procede de este modo: a) para presidentes y/o vicepresidentes de las Asamblea Municipal: el Presidente de la Asamblea Provincial( en lo adelante APPP) o un delegado a la propia Asamblea Municipal, b) para presidentes y/o vicepresidentes de la APPP o del Municipio Especial Isla de la Juventud: el Consejo de Estado o un delegado 
a la propia Asamblea, c) para el presidente, del vicepresidente o el Secretario de la ANPP: el Consejo de Estado o un diputado, y d) para un miembro del Consejo de Estado: el Consejo de Estado o un diputado.

De lo anteriormente expuesto se colige que la propia ciudadanía debe estar facultada para promover procesos de revocación contra todos los cargos de elección popular en las diferentes estructuras del nivel estatal. El desiderátum de la democracia clama para que la revocación debe quedar abierta con un carácter inmediato, sin excepción, a todos los cargos públicos electos, pudiendo ser propuesta por un por ciento de ciudadanos, siendo consecuentes con las bases republicanas del diseño y eliminar lo que parece un defecto de la regulación. Se trataría de ser coherente con la regulación legal del propio diseño.

Las asambleas de rendición de cuentas, también deberían constituir espacios para pronunciar demandas de impacto nacional y para participar de la formulación de líneas programáticas sobre el Gobierno de la nación. Así sean, por ejemplo, las decisiones sobre los programas de gobierno local, provincial y nacional, los cuales no resultan definidos a través del proceso electoral.

Las asambleas de rendición de cuentas deben funcionar como una potencial asamblea de ciudadanos al estilo de los comicios romanos, en los cuales se nominaban, elegían y revocaban a los mandatarios y se aprobaban las normas del ámbito municipal. Si se circunscribe la rendición de cuentas como un mero "dar a conocer» la gestión política de los representantessin más efectos que los que se puedan derivar de esto-, sería reñido inscribirla en el marco del tipo de instituciones que se están analizando. Pero si se concibe en su naturaleza dinámica, a partir de la definición anterior, podría defenderse su calidad de institución republicana inmediata.

Si se analiza el referendo vemos que de acuerdo al Diccionario de Derecho Romano el término proviene de la expresión latina ad referéndum, que hace alusión a la práctica de referir determinadas cuestiones gubernamentales al pueblo. El vocablo 
referéndum procede del verbo refero (fero-"llevar"; re-"de nuevo") que significa volver a llevar, en este caso al pueblo, la soberanía que legítimamente posee. Los ciudadanos son los soberanos y su voluntad política se patentiza por medio de mandatarios políticos, pero determinados temas han de someterse directamente al pronunciamiento popular, a referéndum: deben volver al único depositario de la soberanía.

Tal cual se ha podido apreciar, en el Derecho Romano todas las decisiones políticas se sometían a consultas populares. Y el populus romano, reunido en comicios, decidía ad referéndum las normas que se sometieran a su consideración por parte de los magistrados, para quienes sería vinculante lo que decidiera el populus. Aunque hasta el momento estas no están previstas en normas jurídicas, las consultas populares han sido utilizadas con frecuencia como paso previo a la promulgación de diversas leyes o a la adopción de determinadas decisiones de carácter nacional. El reconocimiento jurídico de estos mecanismos participativos implicaría otorgar legitimidad y fundamento legal a formas democráticas de participación que de hecho se practican y que cuentan con un fuerte respaldo político, pero un escaso respaldo legal, y que son obviamente de inspiración romanista.

Por tanto, se debe definir, en futuras leyes de desarrollo, el carácter vinculante o no de la consulta. Si bien la consulta popular es promovida desde el propio aparato de poder-tal como ocurría en el Derecho Público Republicano Romano-, lo que la diferencia de aquel es que no queda claro el carácter vinculante de la consulta, desaprovechándose así una importante vía de intervención inmediata de la ciudadanía en el proceso de formación de la ley. Incluso, emitiendo sus opiniones desde el nivel municipal de ejercicio del poder. Debe aprovecharse la posibilidad que franquea el artículo 200 del actual texto constitucional para el nivel municipal del ejercicio del poder, espacio per se para el carácter vinculante e inmediato en la toma de decisiones.

Además, si los referendos solo pueden ser convocados por la ANPP, estos abarcarán materias de índole nacional, lo cual 
no potencia su posibilidad de constituirse en mecanismos de democracia inmediata en los ámbitos de provincias, municipios, consejos populares y circunscripciones, para la toma ciudadana de decisiones a tal escala. Es este entonces otro punto de inflexión en el cual nos alejamos del modelo iusromanista.

b) Carácter renovable de los cargos de elección popular.

Otra de las principales líneas políticas que trazó el Informe Central al VI Congreso del Partido Comunista de Cuba, en el marco del perfeccionamiento, es la renovabilidad de los cargos de elección popular. Es este el único principio del iusrepublicanismo romano que hasta la actualidad no se había reconocido en el diseño cubano, pero que ya goza de consagración en el magno texto de 2019.

Recuérdese que en el modelo iuspublicístico romano, el carácter renovable de los cargos de elección popular se erigía en un principio democrático de la Respublica. Hace que todos los ciudadanos puedan participar en la gestión de los asuntos públicos, pero admitir que una magistratura fuese ocupada sin límite de tiempo, conculcaba las bases republicanas y además suponía atribuir a uno de los ciudadanos una situación de privilegio.

Para precaverse contra posibles abusos de autoridad de los magistrados, la Respublica estableció un término fijo: un año, para el desempeño del cargo, con excepción de la dictadura que duraba un máximo de seis meses. Y la censura, que elegida cada cinco años, duraba un máximo de dieciocho meses (TITO LIVIO 2,1,1). Siguiendo a TITO LIVIO se descubre en $(7,42,2)$ que el requisito de la anualidad en las magistraturas permanentes, y el principio democrático que tendió a que una misma persona no ejercitase continuamente una magistratura, llegó a plasmarse en la prohibición de la iteratio, sancionada por primera vez en el 342 a.n.e. Prohibiéndose así que la misma magistratura pudiese ser recubierta por la misma persona antes de diez años. Ya anteriormente se había prohibido la iteratio para la censura, pudiendo ser censor sólo una vez. Del principio de renovabilidad se derivaba la prohibición de acumular cargos 
de magistrados, en el sentido de que quien desempeñaba una magistratura, no podía desempeñar otra al mismo tiempo .

c) Descentralización en el nivel municipal del ejercicio del poder.

Ya se ha dicho y se ha analizado, que no se concibe una república de base romanista sin municipios . Ha de remembrarse que el municipio supuso la presencia de criterios más flexibles en cuanto al equilibrio entre centralización y descentralización. La relación entre la ciudad de Roma y la vida social y cultural que al interior del municipio se desarrollaba, contribuyó a que sus habitantes pudieran tener el control de los asuntos locales. Esto denota cierta autonomía, pero sin dejar de mantener una conexión política con la urbe romana y su política centralizadora. Recuérdese que en lo que se refiere a sus funciones, los munícipes eligen y revocan a los magistrados anuales. Además, aprueban los decretos honoríficos del Senado, aprueban y abrogan las leyes, no sólo a nivel municipal sino que, como se vio anteriormente, intervenían en procesos decisorios a nivel de la ciudad de Roma .

Para PÉREZ y PRIETO ${ }^{17}$, la descentralización supone la distribución de los asuntos públicos en dos niveles: el central (estatal) y el local (municipal) para lo cual resulta imprescindible armonizar el proceso descentralizador con la unidad de los

\footnotetext{
17 La comprensión plena de estos conceptos nos permitirá avanzar con solidez y sin retrocesos en la paulatina descentralización de facultades, desde el Gobierno Central hacia las administraciones locales(...)" "El reforzamiento sistemático de nuestra institucionalidad, será a la vez condición y garantía imprescindible para que esta política de renovación de los cuadros jamás ponga en riesgo la continuidad del socialismo en Cuba", vid en, Informe Central al VI Congreso del PCC. Fuente: Partido Comunista de Cuba. Sitio oficial. [en línea] Disponible en http://www.pcc.cu/congresos_asamblea/cong6.php/mayo de 2014, pp. 14 y 30.Por su parte la Resolución sobre el perfeccionamiento de los órganos del Poder Popular el Sistema Electoral y la División Político Administrativa establece que la integralidad de un proceso de esta naturaleza, demanda variar procedimientos, términos legales y realizar otras adecuaciones en nuestro Sistema Electoral, sobre la base de los principios esenciales que lo sustentan y demuestran su carácter democrático y participativo, disponible en http:// www.cubadebate.cu/especiales/2011/04/18/resolucion-sobre-el-perfeccionamiento-delos-organos-del-poder-popular-el-sistema-electoral-y-la-division-politico-administrativa/.
} 
fines estatales y su fundamento, el centralismo democrático. Es decir, ha de tenerse en cuenta que para el logro de esa armonía, las relaciones funcionales entre los órganos superiores y locales deben desarrollarse teniendo como principios que los inferiores estén bajo el control de los superiores. Y además, que estos últimos garanticen la unidad estatal a través de disposiciones de carácter general y obligatorio que, lejos de limitar, estimulen la iniciativa y responsabilidad de los órganos locales en un actuar más autónomo ${ }^{18}$.

VALDÉZ PAZ ${ }^{19}$ señala que esta cultura se relaciona con el interés de los sujetos y actores políticos de participar en las cuestiones públicas y colectivas, de manera más o menos comprometida, todo lo cual supone una cierta concientización, la identificación con ciertos valores colectivistas, y entender la participación como un valor de la Revolución y de la República. Pero esta concientización no ha de ser vista solamente como fundada en premisas puramente ideológicas en ciertos ideales. Presupone además, en los sujetos y actores, una praxis democrática participativa que la instaure y reproduzca.

Con similar tino defiende LEZCANO PÉREZ ${ }^{20}$ que nuestro país es indivisible, los gobiernos no son independientes, pero deben tener autonomía y usarla con inteligencia y con mucha disciplina, hay que lograr mantener la armonía entre la nación y la localidad.

Continúan asestando PÉREZ y PRIETO que debe ampliarse la capacidad decisoria de los municipios, no solo local cuando los asuntos sean de su competencia, sino influir también en

18 Cfr. PÉREZ HERNÁNDEZ, Lissette y PRIETO VALDÉS, Martha, "La descentralización de las decisiones a favor de los municipios. Un reto y una necesidad de los pueblos", en Temas de Derecho Constitucional Cubano, pp. 196.

19 Vid. VALDÉZ PAZ, Juan, "Notas sobre la participación política en Cuba", en PÉREZ GARCIÁ, Arnaldo J. (compilador), Participación social en Cuba, Centro de Investigaciones Psicológicas y Sociológicas (CIPS), Ciudad de La Habana, 2004 p. 62.

20 Cfr. LEZCANO PÉREZ, Jorge, en ASAMBLEA PROVINCIAL DEL PODER POPULAR. Relatoría del Taller sobre las transformaciones ocurridas en el municipio después de la institucionalización, Matanzas, 2009, p. 6. 
las decisiones más generales, de carácter provincial o nacional. Para ello es imprescindible lograr una conformidad suficiente entre la centralización y la descentralización de las decisiones, tal cual se lograba en el modelo romano de República.

La descentralización significa una activa participación de los entes locales en las decisiones de los superiores, eleva el papel del pueblo como centro de poder y consolida el consenso activo, expresión de legitimidad de los gobernantes, de los mecanismos y del sistema en general.

Por lo tanto, se deberá perfeccionar la participación ciudadana-consecuencia del carácter popular de la soberaníaampliando y fortaleciendo vías que propicien el ejercicio del poder popular efectivo. Se impone regular: cómo, dónde, por qué y para qué participar, estimulándose las iniciativas locales de participación.

Al desarrollar y perfeccionar el Poder Popular, el país está en condiciones de ofrecer al mundo una alternativa democrática más directa.

Al criterio de las autora ${ }^{21}$, se añade que, "con el perfeccionamiento del diseño político-jurídico cubano de la participación ciudadana en el siglo XXI, se estaría reconociendo el valor de la Constitución cubana, la cual consagró, por primera vez en el ámbito latinoamericano, una República democrática de evidentes fundamentos romanistas ".

\section{Conclusiones}

1. En el diseño político-jurídico cubano actual de la participación, sobre bases romanistas y martianas, está establecida la institucionalidad democrática, mediante la cual el pueblo ejerce la democracia inmediata que incluye necesariamente, cuando

21 GONZÁLEZ QUEVEDO, Joanna, "El republicanismo democrático romano. Su impronta para el diseño estructural del modelo clásico de Derecho Público Romano", en Revista de Derechos Humanos y estudios sociales(REDHES), año IV, No.7, enero-junio de 2012, Universidad Autónoma de San Luis de Potosí, México y Universidad de Sevilla, España, p. 66. 
menos, el referéndum de reforma constitucional y de aprobación de la ley; la elección y revocación de la autoridad del ciudadano que ejerce el poder público y el derecho de resistencia contra los actos lesivos a su soberanía.

2. El mayor aporte del iusrepublicanismo romano al diseño político-jurídico cubano, en materia de institucionalidad democrática, se encuentra en el proceso de nominación-elecciónrendición de cuentas y revocación, en el nivel municipal del ejercicio del poder.

3. Dentro de los propios límites del diseño constitucional cubano de la participación política del ciudadano en el ejercicio del poder, constituye una necesidad la modificación en la concepción de algunos de sus preceptos, en futuras leyes de desarrollo, para ser consecuentes con un modelo, que desde sus raíces, ha recepcionado fundamentos romanistas, y así contribuir al perfeccionamiento de la democracia en la actual República de Cuba.

\section{Bibliografía}

Arangio-Ruiz, Vicente (1980) Historia del Derecho Romano. Editorial Biblioteca Jurídica de Autores Españoles y Extranjeros, p. 120.

Catalano, Pierángelo; Fernández Bulte, Julio y Fernández Estrada, Julio Antonio (2000) Constitución y constitucionalismo boy. Editorial Fundación Manuel García-Pelayo. Caracas

Catalano, Pierángelo (2006) "Choque de sistemas jurídicos en la perspectiva latinoamericanista", en Memorias del XV Congreso latinoamericano de Derecho Romano. Morelia.

Cicerón (1902) De República. Editorial

Constitución de la República de Cuba (2019). Ed. Gaceta Oficial Extraordinaria. La Habana

Fernández de Buján, Antonio (2011) Derecho Público Romano. Editorial Civitas. Buenos Aires

García del Corral, Idelfonso (1889) Cuerpo del Derecho Civil Romano. Ediciones Antiguas y Modernas. Barcelona 
González Quevedo, Joanna (2012) "El republicanismo democrático romano. Su impronta para el diseño estructural del modelo clásico de Derecho Público Romano", en Revista de Derechos Humanos y estudios sociales(REDHES). $\mathrm{N}^{\circ} 7$. Universidad Autónoma de San Luis de Potosí, México y Universidad de Sevilla.

- (2013) "Principales aportes del modelo clásico de Derecho Público Republicano Romano para la unidad de principios del republicanismo democrático", en Revista española de Republicanismo "Sin Permiso" . En línea en: www.sinpermiso.info/ articulos/ficheros/11romano.pdf

Informe Central al VI Congreso del PCC (2014). En línea en: http:// www.pcc.cu/congresos_asamblea/cong6.php/mayode2014.com

Lezcano Pérez, Jorge (2009) ASAMBLEA PROVINCIAL DEL PODER POPULAR. Relatoría del Taller sobre las transformaciones ocurridas en el municipio después de la institucionalización. Editorial Matanzas. Matanzas

Lobrano, Giovanni (1996) "Republica e municipi", en Costituzionalismo Latino II, Consiglio Nazionale delle Ricerche Progetto Italia. Verona

Pérez Hernández, Lissette y Prieto Valdés, Martha (2000) "La descentralización de las decisiones a favor de los municipios. Un reto y una necesidad de los pueblos", en Temas de Derecho Constitucional Cubano. Editorial Félix Varela. La Habana.

Rinaldi, Norberto Darío (2002) "La resurrección del Derecho Público Romano" en, Memorias del XIII Congreso Latinoamericano de Derecho Romano. Editorial Universidad de San Nicolás de Hidalgo. Morelia.

- (2007) Lecciones ampliadas de derecho romano. Editorial Edictum. Buenos Aires

Rousseau, Jean-Jacques (2000) El contrato social. Editorial Técnos. Madrid

Rubio Correa, Marcial (1996) "La participación del pueblo en la elaboración constitucional dentro de los países latinoamericanos de Sudamérica”, en Costituzionalismo Latino II, Consiglio Nazionale delle Ricerche Progetto Italia. Verona.

Savigny, Friedrich Carl Von (1879) Sistema de Derecho romano actual. Editorial F. Góngora y Compañía. Madrid 
Torrent, Armando (2002) Derecho Público Romano y sistema de fuentes. Editorial Edisofer S.L, Zaragoza.

Valdéz Paz, Juan (2004) "Notas sobre la participación política en Cuba", en Participación social en Cuba, Centro de Investigaciones Psicológicas y Sociológicas (CIPS). La Habana. 